\title{
Projetos de cultura visual na educação básica: Outros modos de ver a cultura escolar
}

\section{Visual culture projects in basic education: Other ways of seeing the school culture}

Maria Emilia Sardelich ${ }^{1}$

Erinaldo A. do Nascimento ${ }^{2}$

Camylla R. M. Paiva ${ }^{3}$ 


\section{Resumo}

Este artigo apresenta uma das investigações do Grupo de Pesquisa em Ensino das Artes Visuais (GPEAV), da Universidade Federal da Paraíba (UFPB), sobre projetos de Cultura Visual na Educação Básica, em contraste com as concepções de escola e currículo indicadas na Resolução CNE/CEB n. 4/2010. A pesquisa exploratória, de caráter bibliográfico e documental, analisou projetos publicados na Coleção Educação da Cultura Visual, editada pela Universidade Federal de Santa Maria (UFSM). O estudo conclui que os projetos de Cultura Visual na Educação Básica estendem as fronteiras do componente curricular do ensino de arte, devido ao posicionamento pedagógico que prioriza aquele que vê, a subjetividade que se relaciona com as visualidades, aberta a outras interpretações e modos de ver e pensar.

Palavras-chave: Cultura Visual, Visualidade, Educação Básica.

\section{Abstract}

This paper presents one research of Grupo de Pesquisa em Ensino das Artes Visuais (GPEAV), Universidade Federal da Paraíba (UFPB), on Visual Culture projects in Basic Education in contrast to the concepts of school and curriculum, in the Resolution CNE / CEB n . 4/2010. The exploratory research has analyzed published projects in Visual Culture Book Collection, organized by the Universidade Federal de Santa Maria(UFSM). The study concludes that the Visual Culture projects have extended the boundaries of the curricular component of art, due to the pedagogical position that favors whom sees, the subjectivity, opened to other interpretations and ways of seeing and thinking

Keywords: Visual culture, Visuality, Basic Education.

ISSN: 2175-2346

1 Universidade Federal da Paraíba (UFPB) - emilisar@hotmail.com

2 Universidade Federal da Paraíba (UFPB) - erinaldoalves2011@gmail.com

${ }^{3}$ Universidade Federal da Paraíba (UFPB) - ranylly_camylla@hotmail.com 


\section{INTRODUÇÃO}

Uma série de atos normativos vem conformando a Educação Básica (EB) no Brasil desde a década de 1990. A Lei 9.394/96, que estabelece as Diretrizes e Bases da Educação Nacional (LDB), define, em seu artigo 21, a EB como um nível educacional que abrange três etapas articuladas: a Educação Infantil, o Ensino Fundamental e o Ensino Médio. Em seu artigo 26, segundo parágrafo, determina o ensino da Arte, especialmente em suas expressões regionais, como componente curricular obrigatório nas três etapas da EB, de forma a promover o desenvolvimento cultural dos alunos.

Para normatizar as linhas básicas expressas na LDB, a Resolução CNE/CEB n. 4/2010, que constitui as Diretrizes Curriculares Nacionais Gerais para a Educação Básica (DCNEB), nos oferece, em seu artigo 11, a concepção de escola como um espaço em que se ressignifica e se recria a cultura herdada, em que se aprende a valorizar as raízes próprias das diferentes regiões do País. Nesse mesmo artigo ratifica que essa concepção de escola exige a superação do rito escolar, desde a construção do currículo até os critérios que orientam a organização do trabalho escolar em sua multidimensionalidade, ao privilegiar as trocas, o acolhimento e o aconchego, para garantir o bem-estar de crianças, adolescentes, jovens e adultos, no relacionamento entre todas as pessoas. Em relação ao currículo, o artigo 13, assinala que este se configura como o conjunto de valores e práticas que proporcionam a produção, a socialização de significados no espaço social e contribuem, intensamente, para a construção de identidades socioculturais dos educandos. Reforça o entendimento de currículo como experiências escolares que se desdobram em torno do conhecimento, permeadas pelas relações sociais, articulando vivências e saberes dos estudantes contribuindo para construir as identidades dos educandos em percursos formativos abertos e contextualizados em função das peculiaridades do meio e das características, interesses e necessidades dos estudantes. Desse modo, as DCNEB indicam uma concepção de matriz curricular como propulsora de movimento e dinamismo ao organizar o trabalho pedagógico em eixos temáticos. Esse documento enfatiza que a organização em eixos pode concretizar uma proposta pedagógica interdisciplinar, o que possibilitaria superar o isolamento das pessoas e a compartimentalização de conteúdos rígidos nas escolas de EB (BRASIL, 2010).

As DCNEB sinalizam outro modo de ver a cultura escolar. Forquin (1993) define a cultura escolar como o conjunto dos conteúdos cognitivos e simbólicos que "selecionados, organizados, 'normalizados', 'rotinizados', sob o efeito dos imperativos de didatização, constituem habitualmente o objeto de uma transmissão deliberada no contexto das escolas" (FORQUIN, 1993, p. 167). Essas diretrizes apontam para outra visão de "ideias, princípios, critérios, normas e práticas sedimentadas ao longo do tempo das instituições educativas" (VINÃO FRAGO, 2000, p. 100). O artigo 14, das DCNEB, corrobora que a Arte, em suas diferentes formas de expressão, é componente curricular da base nacional comum. No componente curricular Arte, vem se destacando uma perspectiva educacional denominada Cultura Visual.

A Cultura Visual é um campo de estudo que, desde a década de 1980, vem atraindo pesquisadores do âmbito acadêmico da Inglaterra e Estados Unidos, entre 
as fronteiras das Artes e Ciências Humanas. A produção acadêmica sobre a Cultura Visual é extensa e, no Brasil, a Coleção Educação da Cultura Visual, editada pela Universidade Federal de Santa Maria, a partir de 2009, com a organização de Martins; Tourinho $(2014,2013,2012,2011,2010,2009)$ reúne pesquisadores brasileiros e estrangeiros. Apesar dessa acelerada produção acadêmica no País, ainda temos poucos estudos que realizem um balanço sobre o conhecimento produzido. Seria possível reconhecer proposições da Cultura Visual para a mediação pedagógica na EB? De que modo essas proposições se relacionariam com os princípios norteadores definidos na Resolução CNE/CEB n.4/2010?

É a partir desses questionamentos que o Grupo de Pesquisa em Ensino das Artes Visuais (GPEAV), do Departamento de Artes Visuais (DAV), em parceria com o Departamento Metodologia da Educação (DME), da Universidade Federal da Paraíba (UFPB), vem desenvolvendo pesquisas para traçar uma cartografia da produção acadêmica brasileira sobre a Educação da Cultura Visual, no período de 2005-2015. Os resultados que apresentamos neste artigo focalizam os projetos de Cultura Visual, desenvolvidos no âmbito da EB, publicados na Coleção Educação da Cultura Visual. A pesquisa exploratória, de caráter documental e bibliográfico, se constitui em um levantamento do estado do conhecimento com a finalidade de discutir essa produção acadêmica (FERREIRA, 2002). Pretendemos disseminar o conhecimento produzido no emergente campo da Educação da Cultura Visual e, para alcançarmos esses objetivos, apresentamos, a seguir, as características gerais desse campo de estudo; as peculiaridades identificadas em projetos para a EB e, por fim, as considerações alcançadas.

\section{A CULTURA VISUAL}

Como campo emergente de estudo em construção, há muitas divergências entre os estudiosos da Cultura Visual, tanto na delimitação do mesmo quanto no seu objeto de estudo. Apesar da tensão existente entre a recusa de se estabelecer fronteiras ao campo e o interesse em diferenciá-lo, é possível delinear alguns marcos de referência.

$\mathrm{Na}$ linguagem comum do cotidiano utilizamos o vocábulo visual e visualidade como sendo aquilo que vemos e tudo aquilo que é visível. No âmbito da optometria, a vista -o olho, o órgão da visão- é a habilidade para ver algo e a visão a capacidade para compreender o que vemos. A visão implica captar a informação visual, processá - la e dar um significado a essa informação. Por isso a visão é um processo dinâmico, de organização, interpretação e compreensão do que vemos e que está em constante transformação (GIMÉNEZ, 2008). Isso quer dizer que nascemos com a vista, porém a visão é aprendida. Nesse entendimento o significado não está no objeto que se vê, mas sim na relação com o que vemos é que construímos o significado do que foi visto. Berger (1999) observa que aquilo que sabemos ou acreditamos afeta nosso modo de ver as coisas. O autor conjectura que na Idade Média, quando se acreditava na existência física do inferno, é bem provável que a visão do fogo significasse algo muito diferente do que pode significar hoje, como também a própria concepção do 
inferno dependia da visão do fogo que consome a carne, da noção de dor das queimaduras e das cinzas que permanecem. Isso quer dizer que nós também vemos com a visão daqueles com quem convivemos e nos ensinam a ver, o que implica ir muito além da nossa própria vista.

Uma das estudiosas do campo da Cultura Visual, a professora de História da Arte Margaret Dikovitskaya, procurou rastrear esse termo a partir de um levantamento bibliográfico geral. Suas investigações apontam que o termo apareceu pela primeira vez no título de um livro em língua inglesa, intitulado Towards a visual culture: Educating Through Television, que podemos traduzir como Rumo a uma Cultura Visual: educar através da televisão, escrito pelo educador Caleb Gattegno (1911-1988) e publicado em Nova York, em 1969 (DIKOVITSKAYA, 2005). Nesse livro, Caleb Gattegno aborda as possibilidades de formação pela televisão, indicando que, apesar de algumas décadas de uso do meio, este ainda não era explorado com essa finalidade. Vale lembrar que, nos Estados Unidos, os primeiros aparelhos de televisão começaram a ser vendidos ao público em 1939, porém a sua popularização se deu somente a partir de 1945, devido ao conflito bélico conhecido como Segunda Guerra Mundial. Em Rumo a uma Cultura Visual: educar através da televisão, Caleb Gattegno indagava sobre quem seriam os receptores dos programas televisivos, sobretudo quem seriam as crianças que se colocam diante desse aparelho e destacava que os produtores dos programas de televisão deveriam se preocupar em conhecer os receptores, seus interesses e produzir programas dirigidos às expectativas e necessidades dos receptores.

$\mathrm{Na}$ década de 1960, os estudos sobre a recepção também atraiam os pesquisadores que começavam a se organizar em torno do Centre for Contemporary Cultural Studies (Centro Contemporâneo de Estudos Culturais - CCCS), da Universidade de Birmingham, Inglaterra, fundado em 1964. Os primeiros estudos sobre os meios de comunicação, realizados na primeira metade do século $\mathrm{XX}$, criaram uma tradição de pesquisa que enfatizava a emissão e o meio da mensagem. Essa tradição, indagava sobre os efeitos das mídias no receptor privilegiando o emissor da mensagem e o poder do meio. Esse tipo de problematização conduziu a conclusões que enfatizaram o despreparo do receptor para as mensagens veiculadas por esses meios. Os pesquisadores que se organizaram em torno do CCCS de Birmingham, deslocaram o foco dos estudos da função do emissor nos modelos comunicacionais e passaram a perguntar sobre o que as pessoas faziam com os meios de comunicação e os textos veiculados por esses meios. Essa mudança de foco realçou o aspecto cultural da recepção, levantou questões em torno dos significados atribuídos às mensagens e conduziu à denominada "virada cultural", promovida pelos Estudos Culturais (STOREY, 2002).

A "virada cultural", promovida pelos Estudos Culturais contagiou várias tradições disciplinares. No âmbito da História da Arte, uma das primeiras publicações em que o termo Cultura Visual foi utilizado, nos Estados Unidos, é o livro A arte de descrever: arte holandesa no século XVII, de Svetlana Alpers, de 1983. Nesse livro, a autora argumenta que, no século XVII, a Holanda desenvolveu uma "cultura visual" específica. A autora destaca um modo de ver centrado na descrição do mundo, com um preciso registro das coisas visíveis e empenho no desenvolvimento de mapas e artefatos óticos. Alpers (2003) afirma que se propôs a estudar a Cultura Visual e deve esse ter- 
mo a Michael Baxandall, apesar de utilizá-lo de um modo diferente ao de Baxandall. Em seu livro Painting and experience in fifteenthcentury Italy, publicado nos Estados Unidos em 1972, Baxandall utilizou a expressão "olhar de época", o que supõe que os pintores pintariam seus quadros a partir de certos modelos e padrões visuais que são aprendidos, aceitos pelo espectador que desenvolve sua competência visual a partir desses padrões. Isso equivale a dizer que o olhar seria um sentido historicamente construído. Alpers (2003) esclarece que compreendeu a cultura holandesa do século XVII como uma cultura na qual as imagens, comparadas aos textos, eram os elementos centrais da representação do mundo, para a formulação e produção do conhecimento. Por isso deteve-se no estudo das habilidades visuais da cultura holandesa como também constatou que, naquele lugar e tempo, essas habilidades eram determinantes para o conhecimento produzido. Nessa compreensão, a Cultura Visual se diferencia da verbal ou textual, sendo uma noção que especifica suas diferenças. Para Alpers (2003) as fronteiras disciplinares, assim como as diferenças entre os meios artísticos, são matéria de investigação que não devem ser desconsideradas.

No prefácio do livro Vision and Visuality, publicado nos Estados Unidos em 1988, Hal Foster esclarece a razão pela escolha dos termos visão e visualidade para o título. Embora se entenda a visão como operação física e a visualidade como fato social, as duas não se opõem. A visão também é social e histórica, e a visualidade envolve corpo e psique, porém esses termos assinalam uma diferença nos enfoques estudados: os que dão atenção à visão e seus dispositivos, suas técnicas históricas; os que focalizam a visualidade como determinações discursivas, o modo como olhamos que está condicionado pelos mecanismos da visão, como também pelo que nos fazem ver. Nesse sentido, pensar a visualidade implica perguntar sobre de que modo vemos e também como somos capazes, autorizados ou levados a ver (JAY, 2003).

Outra publicação fundamental para a emergência do campo da Cultura Visual é o livro Picture Theory: Essays on Verbal and Visual Representation (Teoria da Imagens: Ensaios sobre a Representação Verbal e Visual), publicado em 1994, de William John Thomas Mitchell, livro no qual cunhou a expressão pictorial turn, "virada imagética", ao se referir ao novo desafio posto no campo das humanidades em torno dos questionamentos sobre a imagem. Nessa obra, Mitchell indaga se a Cultura Visual seria o objeto visual dos Estudos Culturais. O autor assume que a Cultura Visual não existiria sem os Estudos Culturais, como também não existiria sem os Estudos do Cinema, do Feminismo, da Semiótica, da Teoria Literária, da Estética, da História, da Antropologia e muitas outras influências. Para ele a qualidade que diferencia a Cultura Visual reside no fato desse campo nomear uma problemática de estudo e não um "objeto teórico" de contornos definidos e limitantes (MITCHELL, 2009).

Mitchell (2000) compreende que o estudo da visualidade não pode deixar de lado o papel determinante da visão e da imagem na elaboração da própria noção de alteridade cultural. Tampouco pode ignorar as implicações do fetichismo das imagens, nem as pesquisas científicas sobre a fisiologia do olho e do sistema visual em relação aos outros sentidos, bem como as tecnologias da imagem e das diversas próteses do visível. Afirma que o que torna a Cultura Visual estimulante e provocadora é o fato de obrigar o pesquisador explorar as fronteiras culturais, pois tradicionalmente a análise cultural tem privilegiado a linguagem verbal e seus textos. Questiona o ter- 
mo visual na expressão em uso, pois para esse estudioso separar o verbal do visual limita a análise de qualquer texto cultural, pois a tensão entre palavra e imagem está sempre presente. Em razão disso, as representações visuais fazem parte desse conjunto de práticas de discurso, o que seria mais um argumento para pensar as relações verbo visuais.

Ao discutir a expressão "virada imagética", Dikovitskaya (2005) também indica o fato que os Estudos Culturais marcaram a emergência da Cultura Visual, pois a "virada cultural" destacou a relação entre conhecimento e o poder, um dos pressupostos fundamentais desse campo de estudo. Outra publicação que alicerça o campo é An Introduction to Visual Culture (Uma introdução a Cultura Visual), de Nicholás Mirzoeff, em 1999. Mirzoeff (2003) afirma que a visualização caracteriza o mundo contemporâneo, porém essa característica não significa que, necessariamente, conheçamos aquilo que observamos. O autor afirma que a Cultura Visual é uma "tática para estudar a genealogia, a definição e as funções da vida cotidiana pós-moderna a partir da perspectiva do consumidor, mais que do produtor" (MIRZOEFF, 2003, p. 20). Enfatiza que não se trata de uma história das imagens, nem depende das imagens em si mesmas, mas sim dessa tendência de plasmar a vida em imagens ou visualizar a existência, pois o visual é um "lugar sempre desafiante de interação social e definição em termos de classe, gênero, identidade sexual e racial" (MIRZOEFF, 2003, p. 20).

No sentido indicado por Mirzoeff (2003), a Cultura Visual é uma estratégia para compreender a vida contemporânea e não uma disciplina acadêmica. $O$ autor busca compreender a resposta dos indivíduos e dos grupos aos meios visuais de comunicação em uma estrutura interpretativa fluida. Do mesmo modo que os estudos culturais tratam de compreender de que maneira os sujeitos buscam sentido ao consumo, a compreensão de Cultura Visual, sinalizada por Mirzoeff (2003), dá prioridade à experiência cotidiana do visual, se interessa pelos acontecimentos visuais nos quais o consumidor busca informação, significado e ou prazer conectados com a tecnologia visual.

Hernandez (2011) identifica três grandes enfoques para o estudo da Cultura Visual que localizou na bibliografia e propostas pedagógicas que circulam nos encontros de pesquisadores, porém adverte que estes não são fechados, mas que "se vinculam entre si e se hibridizam com outras referências e contribuições" (HERNÁNDEZ, 2011, p. 32). O primeiro enfoque compreende a Cultura Visual como um campo de estudo transdisciplinar ou adisciplinar, que se ocupa das práticas do olhar e seus efeitos sobre quem vê. Essa posição se apresenta com referências ao pós-estruturalismo, estudos culturais, nova história da arte, estudos feministas, entre outros. Enfatiza a noção de visualidade como as representações visuais que carregam e medeiam significados firmando posições discursivas. O segundo enfoque representa "um guarda-chuva posicional", que abriga artefatos visuais do passado e do presente, ocupando-se das práticas de como vemos e somos vistos por esses objetos. Esse entendimento se apresenta com referências à História Cultural da Arte e privilegia o estudo do contexto de produção, distribuição e recepção das representações em relação ao momento histórico no qual vivemos, para revisar os relatos sobre esta e outras épocas, a partir das representações visuais. $O$ terceiro enfoque compreende como uma condição cultural marcada pela relação com a tecnologia visual que afeta 
como vemos, a nós mesmos e ao mundo. Essa compreensão da Cultura Visual não se ocupa de um quê (objetos), nem de um como (caminhos de interpretação para o que vemos), pois se constitui como um espaço relacional que se projeta entre o que vemos e como somos vistos por aquilo que vemos.

Consideramos que o conceito de visualidade, entendido como modos de ver, articula a Cultura Visual como campo de estudo próprio. Desse modo, a Cultura Visual se diferencia da História da Arte por compreender que a visão não é um dado natural e, também, questionar a universalidade da experiência visual. Por isso, a Cultura Visual admite a especificidade cultural dos modos de ver em tempos e espaços que devem ser contextualizados. A tradição disciplinar da História da Arte Ocidental tem privilegiado o que se vê, o objeto, e o produtor do objeto visto, por meio de uma visão disciplinadora. Hernández (2011) destaca que a tradição ocidental sobre a arte e as imagens privilegiou o objeto e o produtor do objeto como um criador individual. Nesse entendimento a visão se dirige para o que é visto e tratado como uma espécie de enigma a ser decifrado com o auxílio da disciplina História da Arte. Nessa tradição tanto a escola como o museu são lugares que disciplinam a visão para ver o que deve ser visto. Essa visão disciplinada e disciplinadora não se pergunta sobre o efeito que aquilo que é visto tem em quem vê. Em relação ao efeito, Hernandez (2011) destaca que, para além do efeito emocional ou evocativo, podemos indagar sobre o efeito posicional e subjetivador.

Para Nascimento (2009) a Cultura Visual, não se centra na biografia de artistas nem na produção de suas obras e tampouco hierarquiza a produção visual, pois se apoia tanto na produção consagrada por galerias e museus, como na dispersa pelos meios de comunicação, que sofrem os efeitos do discurso vigente em cada época. O autor destaca o foco da Cultura Visual como sendo a interpretação do sujeito que vê, independente da análise formal dos elementos visuais, privilegiadas em propostas fundamentadas na Gestalt. Desse modo, não considera um desenvolvimento evolutivo e linear na produção visual, pois imagens do passado e do presente dialogam entre si propiciando meios para aquele que vê poder transitar entre realidades culturais diferentes sejam, ou não, pertencentes ao mesmo momento histórico.

Em nosso entendimento, a Cultura Visual se diferencia de outras propostas de trabalho com as imagens, sejam da arte ou não, por enfatizar a interpretação daquele que vê e não o objeto que é visto, nem o produtor desse artefato. A Cultura Visual privilegia a interpretação daquele que vê, os significados que aquele que vê constrói na medida em que se relaciona com os artefatos visuais, fala e é escutado, sobre a relação que estabelece entre aquilo que vê e seu próprio contexto. Mais do que pensar em representações e artefatos, a Cultura Visual explora os discursos sobre os quais as representações constroem relatos do mundo que habitamos e favorecem determinadas visões sobre o mundo e nós mesmos. Por essa razão, questiona a tentativa de fixar significados nas representações e como isso pode afetar nossas vidas. Também discute as relações de poder que se produzem e se articulam por meio das representações e que podem ser reforçadas pelos modos de ver e produzir essas representações. Por isso, os educadores que se identificam com a abordagem da Cultura Visual estão atentos às imagens que estão nas camisetas, nos celulares, nos "notebooks", nas pastas e cadernos dos educandos; os programas de televisão a que assistem; as 
séries que perseguem e estendem seus enredos; dos jogos preferidos; das revistas que leem; suas roupas; grupos musicais e outros objetos de culto.

\section{PROJETOS DE CULTURA VISUAL NA EDUCAÇÃO BÁSICA}

Neste tópico apresentamos as narrativas referentes aos projetos de trabalho desenvolvidos com estudantes das escolas de EB, publicados na Coleção Educação da Cultura Visual, organizada por Martins; Tourinho (2013, 2012, 2009). No estudo desses projetos não pretendemos definir um encadeamento de procedimentos, nem sequer encontrar "o caminho" para desenvolver projetos de Cultura Visual. Consideramos que esta abarca muito mais que um campo de estudo, pois se caracteriza como uma "metodologia viva", "uma atitude intelectual, uma sensibilidade que nomeia uma problemática" (HERNANDEZ, 2013), logo os procedimentos estarão sujeitos ao contexto que deflagrar o projeto. Por isso nossa intenção é compartilhar a reflexão desses pesquisadores e avistar possibilidades para se pensar as visualidades na EB em contraste com a concepção de escola e currículo indicados na Resolução CNE/CEB n.4/2010.

Analisamos as narrativas referentes a oito projetos de trabalho: Arantes (2009), Alves; Andrade (2013), Nascimento (2009), Pereira; Martins (2009), Pla (2013), Tavin (2009), e Ucker (2009). Também destacamos os desafios presentes nos referenciais curriculares do Ensino Fundamental do estado da Paraíba, para o componente curricular Arte, organizado a partir da relação entre educação e visualidades, sem a prescrição de conteúdos prévios seriados (NASCIMENTO, 2012).

Arantes (2009) trabalhou em uma escola pública brasileira de Belo Horizonte, da etapa do Ensino Fundamental, com estudantes entre 14 e 15 anos de idade, buscando compreender, a partir das perspectivas dos discentes, como se davam as suas relações com e dentro da escola, como também o que a escola representava para eles. Utilizou o cinema como artefato visual para, a partir deste, problematizar as noções naturalizadas de "aluno" e encorajar esses estudantes a contar suas histórias a partir das relações que estabeleceram com os filmes. A autora procurou entender as razões pelas quais, no seu entendimento, a escola funciona menos para aqueles que dela mais necessitam, sobretudo as escolas publicas voltadas para a classe trabalhadora, pois considera que destacar as relações de poder que, normalmente determinam os limites territoriais, sociais, econômicos e intelectuais dos estudantes, "possibilitaria uma visão mais crítica sobre si mesmos e sobre seus contextos" (ARANTES, 2009, p. 31-32).

Alves; Andrade (2013) utilizaram o artefato vídeo para que discentes e docentes de uma escola de EB, do Rio de Janeiro, produzissem suas próprias histórias. Nesse projeto, discentes e docentes produziram três curtas-metragens: o primeiro sobre como entendem a escola; o segundo como a apropriação do conhecimento também forma nossa subjetividade e o terceiro sobre a história da própria escola. Para as autoras as imagens e os sons produzidos por discentes e docentes ainda muito têm a nos dizer. Por isso, discutiram os problemas da escola com a própria comunidade escolar, procurando "compreender os processos de produção do conhecimento e de significações, entendendo que a superação do que muitos vêm chamando de 'crise da escola' só pode ser pensada com a intensa participação deles mesmos" (ALVES; 
ANDRADE, 2013, p. 150).

Nascimento (2009) relata um projeto realizado com estudantes do Ensino Fundamental, de uma escola pública de João Pessoa que, a partir do conteúdo de Arte na antiguidade egípcia, buscaram elementos dessa produção artística na contemporaneidade. Discentes e docentes investigaram os túmulos de um cemitério da cidade, compreendendo como nesse espaço também se manifestam diferenças, não somente religiosas, mas também de classe. Pereira; Martins (2009) também trabalharam com estudantes do Ensino Fundamental a partir dos desenhos pedagógicos e cartazes, de uma escola ribeirinha do Distrito de Igarapé da Fortaleza, Macapá. Para esses autores os desenhos pedagógicos e cartazes da escola são cúmplices de uma narrativa educacional dominante, que sistematicamente normaliza as relações sociais, subjetividades e identidades, cujo principal objetivo é o adestramento dos excluídos ao destino da exclusão. Para os autores, os desenhos pedagógicos e os cartazes dessa escola carregam mensagens de felicidade, dirigindo os olhares dos estudantes para uma suposta felicidade, que conforma um estilo de vida resignado, normalizado, naturalizado, dócil, para desviar a visão desses estudantes das desigualdades étnicas, sociais, econômicas do contexto em que vivem. Os autores destacam que os discentes desejam se identificar com as mensagens de felicidade e alegria presentes nos desenhos pedagógicos e cartazes da escola para serem socialmente aceitos.

Pla (2013) trabalha a partir de vários artefatos visuais -imagens de revistas, fotografias pessoais, colagens- para que estudantes do Ensino Médio, de uma escola espanhola, desenvolvam projetos em torno de seus imaginários visuais. O autor esclarece que a noção de imaginário visual é mais ampla que o repertório de imagens com os quais os estudantes se relacionam, pois além das imagens também abarca o conjunto de visões, comportamentos e valores que conformam a identidade social e cultural. Pla (2013) destaca que os estudantes nem sempre compartilham as formas de relação com os saberes, nem dispõem das mesmas ferramentas intelectuais, que as nossas para interrogá-los. Por isso, como docente, dispõe-se a reconhecer e se aproximar das formas de produção cultural dos estudantes, pois considera os estudantes como "produtores culturais e não como meros consumidores" (PLA, 2013, p. 171). Enfatiza que reconhecer a autoria dos estudantes, e também seus processos de aprendizagem, abala as narrativas dominantes que planejam o lugar que devem ocupar os sujeitos na relação escolar. Reforça que o aprender está relacionado com a elaboração de uma conversa cultural e conversar é uma oportunidade de conhecer o outro, por isso propõe-se a construir o "nós da relação pedagógica em que caibam as múltiplas subjetividades que ocupam tanto dentro como fora da escola" (PLA, 2013, p. 154). Tavin (2009) realizou seu projeto de Cultura Visual com estudantes do Ensino Médio, de uma escola dos Estados Unidos, que denominou "construção de presidentes". Seu objetivo foi interpretar formas contemporâneas de produção imagética que empregam significantes associados a mensagens políticas nas campanhas para presidente dos Estados Unidos, com a finalidade de que os estudantes compreendessem como as imagens do cotidiano ajudam a construir sentidos, e como elas atuam como um catalisador para determinadas ações. Para o autor, o trabalho realizado com e pelos estudantes a respeito dos problemas sociais, e suas possíveis soluções, revela como estes se envolvem com essas questões, porém nem sempre suas vozes, ideias 
e proposições são ouvidas, o que pode levar docentes, e demais adultos, a considerá -los como alienados dessa problemática, como também sobre o que pode constituir uma mudança significativa em suas próprias vidas e do contexto social.

O projeto de Ucker (2009) também se dirigiu aos estudantes do Ensino Médio, de uma escola pública de Goiânia, no Brasil. Esse projeto teve por objetivo analisar como discentes percebem, representam e imaginam suas escolas. A autora concluiu que a conscientização acerca de atitudes e comportamentos na escola pela escola, criou um tipo de percepção que pareceu mostrar aos estudantes algumas possibilidades de transformação e a colaboração como um caminho para refazer a escola como um espaço de lugares onde a vida vive, e busca ser vivida com mais intensidade; um espaço no qual se pode conviver, conversar, socializar. Por meio de desenhos e falas, os estudantes refletiram sobre padrões de comportamento em relação à instituição escolar, como pichar, sujar, negar-se ao uso, que julgam e criticam. A produção imagética dos discentes revelou a precariedade das instalações escolares e como o descuido destas ensina o descaso, o empobrecimento, o isolamento e a marginalização para com todos que ali circulam. O espaço escolar como meio de organização e relação social é uma criação social. Nos espaços imaginados pelos estudantes envolvidos nesse projeto, a escola é "sem grade e, com isso, assinalam abertura e vontade de uma escola que abrigue outras lógicas, estabeleça vínculos com o mundo externo a ela e se distancie de seu papel controlador" (ULCKER, 2009, p. 96).

Nascimento (2012) destaca que na experiência de elaboração dos referenciais curriculares do ensino fundamental para o componente curricular Arte, a partir da relação entre educação e visualidade, a equipe responsável incorporou o conceito de visualidade como os diversos tipos e modalidades de imagens, produzidas em vários contextos culturais e temporais, como também as possíveis maneiras de interpretá -las. Enfatiza que, nesse entendimento, as imagens veiculam discursos subjetivantes e culturais, estabelecendo relações de saber e poder que não se restringem ao poder econômico devido aos preços da comercialização, fama do produtor ou conservador das imagens, mas, sobretudo "na capacidade das imagens fixarem, manter ou romper com as práticas discursivas vigentes" (NASCIMENTO, 2012, p. 315). Esse fato implica muito mais do que dispor de imagens diferentes nas práticas escolares, pois desafia a capacidade de refletir sobre a maneira como afetam a vida dos sujeitos. Essa proposta curricular assumiu deslocar o foco do ensino de conteúdos para a aprendizagem, para a atuação, para a interação social e para a solução de problemas na e da vida. Reconheceu que esses problemas só podem ser compreendidos na medida da sua solução, logo considera que não se criam conceitos, a não ser em razão dos problemas classificados como importantes para serem enfatizados ou priorizados no ambiente escolar. Desse modo, os referenciais curriculares dessa proposta não prescrevem conteúdos previamente, pois partem do pressuposto que os conteúdos dependem das dinâmicas vivenciadas no ambiente escolar. Os referenciais propõem o trabalho pedagógico organizado a partir de três eixos. O primeiro refere-se aos nossos problemas, aos questionamentos enfrentados na contemporaneidade e relacionados com o que somos e vivemos; como as visualidades projetam e nos fazem ver de um determinado modo aquilo que vemos, dizemos, pensamos e somos nos dias atuais. Os conceitos fundamentais desse eixo tratam da identidade, alteridade, sub- 
jetividade. O segundo eixo transita pela nossa história ou nosso passado, problemas decorrentes de visões e atitudes herdadas do passado, transmitidas pelas visualidades, e que ainda afetam o presente. O modo como o passado demarca o que somos no presente circula em conceitos como temporalidades, história, memória, construções sociais, permanências ou continuidades, ruptura, descontinuidade, patrimônio cultural. O terceiro eixo problematiza a situação vigente ou herdada do passado para pensar como se pode viver ou ser um pouco diferente do que se vive ou se é. Nessa perspectiva o presente é uma condição de possibilidades que pode vir a ser diferente de como é. Logo, os conceitos explorados giram em torno da mudança, possibilidade e devir. Esses referenciais não elencam conteúdos, mas se aproximam de possíveis indagações que podem desencadear os conceitos para cada etapa da EB. Por isso apontam questões em torno do: ser criança, viver a infância e seus devires; ser adolescente, viver a adolescência e seus devires; ser jovem, viver a juventude e seus devires; ser adulto, viver a fase adulta e seus devires.

\section{CONSIDERAÇÕES ALCANÇADAS}

A análise desses projetos revelou alguns pontos em comum entre eles. Esses projetos não propõem aprender um meio, uma técnica, mesmo que isso possa acontecer em alguns destes. Todos trabalham com problemas, questões, que surgem a partir das imagens, sejam imagens da arte ou não. Discutem estereótipos, não só de classe social ou gênero, mas, sobretudo noções estereotipadas sobre o próprio processo pedagógico. O ponto em comum de todos esses projetos de Cultura Visual é a característica da reflexibilidade, tanto de discentes como de docentes, que olham para si mesmos na tentativa de compreenderem seus contextos, como também seus posicionamentos nesses contextos.

A partir do exposto, podemos concluir que esses projetos de Cultura Visual se fundamentam em um posicionamento pedagógico que prioriza quem vê, a subjetividade que se relaciona com a imagem, aberta a outras interpretações e modos de ver e pensar. Esse posicionamento pedagógico está em consonância com a concepção de escola expressa na Resolução CNE/CEB n. 4/2010, como um espaço em que se ressignifica e se recria a cultura herdada, reconstruindo-se as identidades culturais, em que se aprende a valorizar quem se é. Situa-se em favor da socialização de significados no espaço social, das trocas e do acolhimento para garantir o bem-estar daqueles que constituem o espaço escolar em seus múltiplos relacionamentos de crianças, adolescentes, jovens e adultos.

Os projetos de Cultura Visual analisados são experiências permeadas pelas relações sociais, que articulando vivências e saberes dos estudantes contribuem para construir suas identidades em percursos formativos abertos e contextualizados, em função das peculiaridades de seus modos de vida. Procuram organizar o trabalho pedagógico em eixos temáticos ampliando a visão disciplinar, ainda arraigada em nossos contextos escolares. Valorizam a experiência do sujeito que vê, contribuindo para a construção de identidades afirmativas e propiciando meios para transitar entre realidades culturais diferentes. Essa consonância revela-se no diferencial da Cultura Visual, em relação a outras propostas para o trabalho com as imagens, se- 
jam da arte ou não, que é o fato de focalizar a interpretação daquele que vê e não o objeto que é visto, nem o produtor desse objeto. Ao privilegiar a interpretação, os significados que aquele que vê constrói na medida em que se relaciona com os artefatos visuais, fala e é escutado, sobre a relação que estabelece entre aquilo que vê e seu próprio contexto, propicia o reconhecimento dos diversos modos próprios de ser, agir e expressar-se.

Consideramos que os projetos de Cultura Visual estendem as fronteiras do componente curricular do ensino de Arte. Essa extensão não é consequência da inclusão de imagens da mídia e ou do cotidiano, nem sequer de uma celebração das imagens consumidas pelos estudantes, mas resulta de um posicionamento pedagógico que prioriza quem vê, a subjetividade que se relaciona com as visualidades, aberta a outras interpretações e modos de ver e pensar. Esse posicionamento pedagógico explicita o poder das imagens compreendendo que toda e qualquer imagem, inclusive as eleitas para a mediação pedagógica, também são produzidas a partir de uma visão que, consequentemente, coloca o discente em uma determinada posição. Desse modo, o que importa não é a imagem, pois nenhuma imagem aliena ou empodera por si mesma, apesar da intencionalidade do produtor da imagem, mas é a ação das pessoas, o que elas fazem com e a partir das imagens para suas próprias vidas. É um posicionamento pedagógico que fomenta oportunidades de interpretação, chances para discentes e docentes construírem outra narrativa, outro modo de se colocar diante das imagens, em seu contexto, seu mundo. Nesse sentido, trabalhar com a Cultura Visual na EB implica entrever brechas para além das interpretações já existentes. Interpretações que tentam, de um modo ou outro, fixar determinados significados. Por isso mesmo esse posicionamento pedagógico necessita de cuidado e atenção, para que o trabalho em torno dos imaginários visuais dos discentes não se comprometa com o olhar regulador e disciplinador do aparato escolar.

\section{Referências Bibliográficas}

ALPERS, Svetlana. Cuestionário October sobre Cultura Visual. Revista Estudios Visuales, n. 1, p. 83-126, nov. 2003.

ALVES, Nilda; ANDRADE, Nívea. Histórias possíveis entre imagens: conhecimentos e significações na produção de vídeos em escolas. In: MARTINS, Raimundo; TOURINHO, Irene. Processos \& Práticas de Pesquisa em Cultura Visual \& Educação. Santa Maria: Ed. Da UFSM, 2013. p. 135-151.

ARANTES, Kelly Christina Mendes. In: MARTINS, Raimundo; TOURINHO, Irene. (orgs.) Educação na cultura visual: narrativas de ensino e pesquisa. Santa Maria: Ed. da UFSM, 2009. p. 17-38

BERGER, John. Modos de ver. Rio de Janeiro, Rocco, 1999. 
BRASIL. Resolução CNE/CEB 4/2010. Diário Oficial da União, Seção 1, p. 824, Brasília, 14 de julho de 2010.

DIKOVITSKAYA, Margaret. Visual Culture: The Study of the Visual after the Cultural Turn. Cambridge (MA): The MIT Press, 2005.

FERREIRA, Norma Sandra de Almeida. As pesquisas denominadas estado da arte. Educação \& Sociedade, n. 79, p. 257-272, Agosto/2002.

FORQUIN, Jean Claude. Escola e cultura: as bases sociais e epistemológica do conhecimento escolar. Porto Alegre: Artes Médicas, 1993.

GIMÉNEZ, María Pilar Vergara. Tanta inteligencia, tan poco rendimiento: ¿podría ser la visión la clave para desbloquear su aprendizaje? Madrid: Edit. Pilar Vergara, 2008.

HERNÁNDEZ, Fernando. Pesquisar com imagens, pesquisar sobre imagens: revelar aquilo que permanece invisível nas pedagogias da cultura visual. In: MARTINS, Raimundo; TOURINHO, Irene. Processos \& Práticas de Pesquisa em Cultura Visual \& Educação. Santa Maria: Ed. Da UFSM, 2013.p. 77-95.

HERNANDEZ, Fernando. A Cultura Visual como um convite à deslocalização do olhar e ao reposicionamento do sujeito. In: MARTINS, Raimundo; TOURINHO, Irene. Educação da Cultura Visual: conceitos e contextos. Santa Maria: Ed. Da UFSM, 2011. p. 31-50.

JAY, Martin. Relativismo Cultural e a Virada Visual. Aletria: Revista de Estudos de Literatura, v. 10/11, p. $14-28,2003$.

MARTINS, Raimundo; TOURINHO, Irene. Pedagogias Culturais. Santa Maria: Ed. da UFSM, 2014.

MARTINS, Raimundo; TOURINHO, Irene. Processos e Práticas na Pesquisa em Cultura Visual \& Educação. Santa Maria: Ed. da UFSM, 2013.

MARTINS, Raimundo; TOURINHO, Irene. Culturas das Imagens. Santa Maria: Ed. da UFSM, 2012.

MARTINS, Raimundo; TOURINHO, Irene. Educação da Cultura Visual: conceitos e contextos. Santa Maria: Ed. da UFSM, 2011.

MARTINS, Raimundo; TOURINHO, Irene. Cultura Visual e Infância. Santa Maria: Ed. da UFSM, 2010.

MARTINS, Raimundo; TOURINHO, Irene. Narrativas de Ensino e Pesquisa na Educação da Cultura Visual. Santa Maria: Ed. da UFSM, 2009. 
MIRZOEFF, Nicholás. Una introducción a la cultura visual. Barcelona: Paidós, 2003.

MITCHELL, William John Thomas. Teoria de la imagen. Madrid: Ediciones Akal, 2009.

MITCHELL, William John Thomas. ¿Qué es la cultura visual? Jornadas Más allá de la educación artística. Cultura visual, política de reconocimiento y educación. Barcelona: Fundación La Caixa, 5 y 6 de noviembre, 2000. [Traducción del texto "What Is Visual Culture?" In: Irving Lavin (Ed.) Meaning in the Visual Arts: Essays in Honor of Erwin Panofsky's 100th Birthday. Pricenton: Institute for Advance Studies,1995. p. 207-217].

NASCIMENTO, Erinaldo Alves do. Culturas das imagens e os desafios dos referenciais curriculares do Ensino Fundamental do Estado da Paraíba: Artes. In: MARTINS, Raimundo; TOURINHO, Irene. Culturas das Imagens. Santa Maria: Ed. da UFSM, 2012.p. 311-328.

Representações da morte para aproximar a escola da vida: uma experiência com a cultura visual no Ensino Básico. In: MARTINS, Raimundo; TOURINHO, Irene. (orgs.) Educação na cultura visual: narrativas de ensino e pesquisa. Santa Maria: Ed. da UFSM, 2009. p. 39-78.

PEREIRA, Alexandre; MARTINS, Raimundo. Sintam-se felizes em nosso ambiente escolar. In: MARTINS, Raimundo; TOURINHO, Irene. (orgs.) Educação na cultura visual: narrativas de ensino e pesquisa. Santa Maria: Ed. da UFSM, 2009. p. 61-78

PLA, Alfred Porres. Conversações na aula de cultura visual. In: MARTINS, Raimundo; TOURINHO, Irene. Processos \& Práticas de Pesquisa em Cultura Visual \& Educação. Santa Maria: Ed. Da UFSM, 2013. p. 153-180.

STOREY, John. Teoria cultural y cultura popular. Barcelona: Octaedro-EUB, 2002.

TAVIN, Kevin. Contextualizando visualidades no cotidiano: problemas e possibilidades do ensino da cultura visual. In: MARTINS, Raimundo; TOURINHO, Irene. (orgs.) Educação na cultura visual: narrativas de ensino e pesquisa. Santa Maria: Ed. da UFSM, 2009. p. 225-239.

UCKER, Lilian. Entre o real e o imaginado: desenhos de espaços escolares. In: MARTINS, Raimundo; TOURINHO, Irene. (orgs.) Educação na cultura visual: narrativas de ensino e pesquisa. Santa Maria: Ed. da UFSM, 2009. p. 79-100.

VINÃO FRAGO, Antonio. El espacio y el tiempo escolares como objeto histórico. Contemporaneidade e Educação, Rio de Janeiro, n.7, p. 100-101, 2000. 


\section{Autores}

Maria Emilia Sardelich

Universidade Federal da Paraíba (UFPB) - emilisar@hotmail.com

Erinaldo A. do Nascimento

Universidade Federal da Paraíba (UFPB) - erinaldoalves2011@gmail.com

Camylla R. M. Paiva

Universidade Federal da Paraíba ( UFPB) - ranylly_camylla@hotmail.com 